\title{
A review of the Hispanic paradox: time to spill the beans?
}

\author{
Robert P. Young ${ }^{1,2}$ and Raewyn J. Hopkins ${ }^{1}$ \\ Affiliations: ${ }^{1}$ Faculty of Medical and Health Sciences, University of Auckland, Auckland, New Zealand. ${ }^{2}$ School \\ of Biological Sciences, University of Auckland, Auckland, New Zealand.
}

Correspondence: Robert P. Young, Respiratory Genetics Group, PO Box 26161, Epsom 1344, Auckland, New Zealand. E-mail: robertylaadhb.govt.nz

ABSTRACT Past epidemiological observations and recent molecular studies suggest that chronic obstructive pulmonary disease (COPD) and lung cancer are closely related diseases, resulting from overlapping genetic susceptibility and exposure to aero-pollutants, primarily cigarette smoke. Statistics from the American Lung Association and American Cancer Society reveal that mortality from COPD and lung cancer are lowest in Hispanic subjects and generally highest in African American subjects, with mortality in non-Hispanic white subjects and Asian subjects in between. This observation, described as the "Hispanic paradox", persists after adjusting for confounding variables, notably smoking exposure and sociodemographic factors. While differences in genetic predisposition might underlie this observation, differences in diet remain a possible explanation. Such a hypothesis is supported by the observation that a diet high in fruit and vegetables has been shown to confer a protective effect on both COPD and lung cancer. In this article, we hypothesise that a diet rich in legumes may explain, in part, the Hispanic paradox, given the traditionally high consumption of legumes (beans and lentils) by Hispanic subjects. Legumes are very high in fibre and have recently been shown to attenuate systemic inflammation significantly, which has previously been linked to susceptibility to COPD and lung cancer in large prospective studies. A similar protective effect could be attributed to the consumption of soy products (from soybeans) in Asian subjects, for whom a lower incidence of COPD and lung cancer has also been reported. This hypothesis requires confirmation in cohort studies and randomised control trials, where the effects of diet on outcomes can be carefully examined in a prospective study design.

○ @ERSpublications

High fibre (bean-based) diet may reduce COPD and lung cancer risk through inhibition of systemic inflammation http://ow.ly/u6tlc

\section{Introduction}

From a public health perspective, the burden of lung cancer and chronic obstructive pulmonary disease (COPD) is significant. Lung cancer accounts for $\sim 25 \%$ of annual deaths from cancer in the USA and COPD is the fourth leading cause of death (around 160000 and 130000 deaths per annum, respectively) [1,2]. While cigarette smoking accounts for $80-90 \%$ of all COPD and lung cancer cases, only $15-20 \%$ of smokers are affected by these diseases $[3,4]$. Indeed, COPD and lung cancer are relatively rare in the absence of a smoking or alternate aero-pollutant exposure. Established risk factors underlying these diseases are age, degree of smoking exposure, family history and diet [1-4], where the regular consumption of fruit and vegetables has been shown to have a protective effect $[5,6]$. This protective effect is relatively strong, even after correction for other variables like smoke exposure, and suggests diet may modify, to some degree, the harmful effects of

For editorial comments see page 410 .

Received: Jan 232014 | Accepted after revision: Jan 312014

Conflict of interest: Disclosures can be found alongside the online version of this article at err.ersjournals.com

Provenance: Submitted article, peer reviewed.

Copyright OERS 2014. ERR articles are open access and distributed under the terms of the Creative Commons Attribution Non-Commercial Licence 4.0. 
smoking. Although the underlying basis of this protective effect is not known, it is believed to stem from the collective antioxidant effects derived through consuming a diet rich in fruit and vegetables $[5,6]$.

\section{The COPD-lung cancer link}

Recent molecular studies support past epidemiological observations suggesting COPD and lung cancer are linked by more than just smoking exposure [7]. Using spirometry, COPD has been found to predate lung cancer in $50-70 \%$ of lung cancer cases, two-to-three-fold the observed prevalence of COPD in age and smoking matched groups $[8,9]$. Indeed, when age and smoking are accounted for, the presence of COPD (characterised by a reduced forced expiratory volume in $1 \mathrm{~s} \%$ predicted) is the strongest predictor of lung cancer [9]. Interestingly, the risk variables of age and pack-years have been shown to have a strong interactive effect on disease risk, with an exponential rise in disease prevalence observed in smokers compared with nonsmokers, above the age of 45 years in COPD and 65 years in lung cancer [10, 11]. While there is growing evidence that the genetic factors underlying susceptibility to COPD and lung cancer are overlapping $[7,12,13]$, there is also evidence for both diseases that the consumption of fruit and vegetables is protective $[5,6]$. This raises the question: what mechanism that links susceptibility to COPD and lung cancer might also be influenced by diet?

\section{Systemic inflammation in the COPD-lung cancer link}

Smoking is recognised as a critical initiating insult to the bronchial epithelium, triggering a strong pulmonary innate immune response, in those who develop COPD and lung cancer [14-16]. However, there is also evidence that systemic inflammation plays a primary role in the development (and possibly progression) of these diseases $[15,16]$. This conclusion comes from numerous prospective studies showing that markers of systemic inflammation, notably elevated interleukin (IL)-6 or C-reactive protein (CRP), are consistently associated with an increased risk of COPD and lung cancer in both population and cohort studies [17-24]. In several prospective studies, elevated markers of systemic inflammation have been repeatedly associated with a decline in lung function in young adults [17-19] and COPD in adults [20-22]. Similarly, in numerous prospective studies of cancer, elevated systemic markers have been associated with the development of lung cancer 5-15 years later [23-27]. Further evidence supporting a role for systemic inflammation in COPD and lung cancer comes from animal studies showing overexpression of IL-6 is linked to the development of COPD and that systemic inflammation in a nonsmoking murine model is linked to innate immune response-mediated DNA damage in the bronchial epithelium [28-31]. This increase in systemic inflammation may result from either an overactive bronchial epithelial response to smoking or an underlying primary hyper-immune response of the innate immune system, or both [28-31]. Support for the latter comes from studies showing systemic inflammation is linked to many cancers, where smoking (or obesity) are known risk factors, although the link is strongest for lung cancer [23-27]. Systemic inflammation, to varying degrees, affects between $50 \%$ and $70 \%$ of those with COPD and lung cancer $[20,22,26]$. There are then bidirectional effects between smoking-induced airway inflammation and "inherent" systemic inflammation, where the latter may be responsible for persisting neutrophilic inflammation in the lungs [16]. This, in turn, contributes to the aberrant repair-remodelling processes underlying COPD that result from a protease-antiprotease imbalance, excessive oxidative stress and progressive DNA damage [16]. In such a microenvironment, rich in metalloproteases and growth factors, both epithelial remodelling (epithelial turnover, and mucous gland hyperplasia and metaplasia) and mesenchymal remodelling (small airway fibrosis, emphysema and epithelial-mesenchymal transition) may contribute to the development or progression of lung cancer [16]. Therefore, we propose that attenuation of systemic inflammation might be one of the critical pathophysiological processes linking diet with smokingrelated lung disease. Indirect support for this hypothesis comes from numerous studies showing that 3-hydroxy-3-methylglutaryl coenzyme A (HMGCoA)-reductase inhibitors (statins), which are powerful inhibitors of systemic inflammation, confer strong protective effects in COPD and lung cancer [16, 31-33]. The question then arises, what other factors, apart from a diet rich in fruit and vegetables, have been associated with a reduced susceptibility to COPD and lung cancer?

\section{The Hispanic paradox}

Statistics from both the American Lung Association and American Cancer Society show that in the USA, the incidence of lung cancer is greatest in African American subjects followed by non-Hispanic white subjects and Asian subjects, with Hispanic subjects having consistently the lowest incidence (table 1 and fig. 1) [37-39]. These inter-ethnic differences in susceptibility to lung cancer persist after correction for many leading confounding variables such as smoking and low socioeconomic status [40,41]. These studies consistently report a $40-50 \%$ reduction in the risk of lung cancer in Hispanic subjects compared with white subjects, a finding recently confirmed in a large prospective study of lung cancer screening in 53000 current or former smokers [41]. In this study, after adjustment for age, smoking history and educational level, the risk of lung 
TABLE 1 Basis of the Hispanic paradox based on incidence, prevalence and mortality figures for chronic obstructive pulmonary disease (COPD) and lung cancer in USA and South American populations comparing Mexican/Hispanic with other ethnicities

\begin{tabular}{|c|c|c|c|c|c|}
\hline Disease & Clinical phenotype & Comparison & Outcome \% & $\begin{array}{l}\text { Risk } \\
\text { reduction \% }\end{array}$ & $\begin{array}{l}\text { First author } \\
\text { [ref.] }\end{array}$ \\
\hline \multirow[t]{9}{*}{ COPD } & $\begin{array}{l}\text { COPD prevalence }(\%) \text { over } 2007-2009 \\
\text { among adults aged } \geqslant 18 \text { years }\end{array}$ & Mexican versus non-Hispanic white & 2.6 versus 5.7 & 54 & AKINBAMI [34] \\
\hline & & Mexican versus Puerto Rican & 2.6 versus 6.9 & 62 & \\
\hline & $\begin{array}{l}\text { COPD prevalence unadjusted (GOLD) } \\
\text { Prevalence of rapid FEV1 decline }\end{array}$ & Mexican versus non-Hispanic white & 14.9 versus 29.5 & 50 & BRUSE [35] \\
\hline & & Mexican versus non-Hispanic white & 21.6 versus 31.6 & 32 & \\
\hline & $\begin{array}{c}\text { COPD prevalence in two Latin } \\
\text { American cities ladjusted for smoking } \\
\text { and ethnicityl }\end{array}$ & Mexico City versus Montevideo & 12.7 versus 20.3 & 37 & MENZES [36] \\
\hline & $\begin{array}{l}\text { COPD mortality rates (2006) } \\
\text { (age-adjusted per } 100000 \text { per year) }\end{array}$ & Hispanic versus Caucasian (males) & 21.2 versus 50.5 & 58 & $\begin{array}{l}\text { American Lung } \\
\text { Association [37] }\end{array}$ \\
\hline & & Hispanic versus American Indian (males) & 21.2 versus 32.2 & 34 & \\
\hline & & Hispanic versus Caucasian (females) & 13.1 versus 39.1 & 66 & \\
\hline & & Hispanic versus American Indian (females) & 13.1 versus 28.6 & 54 & \\
\hline \multirow[t]{12}{*}{$\begin{array}{l}\text { Lung } \\
\text { cancer }\end{array}$} & $\begin{array}{l}\text { Lung cancer incidence rates 2002-2006 } \\
\text { (age-adjusted per } 100000 \text { per year) }\end{array}$ & Hispanic versus Caucasian (males) & 43.2 versus 77.6 & 44 & $\begin{array}{l}\text { American Lung } \\
\text { Association [38] }\end{array}$ \\
\hline & & Hispanic versus American Indian (males) & 43.2 versus 51.6 & 16 & \\
\hline & & Hispanic versus Caucasian (females) & 24.7 versus 54.8 & 55 & \\
\hline & & Hispanic versus American Indian (females) & 24.7 versus 39.8 & 38 & \\
\hline & $\begin{array}{l}\text { Lung cancer incidence rates 1999-2003 } \\
\text { (age-adjusted per } 100000 \text { per year) }\end{array}$ & Hispanic versus Caucasian (males) & 52.7 versus 88.8 & 41 & HowE [39] \\
\hline & & Hispanic versus Caucasian (females) & 26.7 versus 56.2 & 52 & \\
\hline & $\begin{array}{l}\text { Lung cancer mortality rates 2002-2006 } \\
\text { (age-adjusted per } 100000 \text { per year) }\end{array}$ & Hispanic versus Caucasian (males) & 33.9 versus 69.9 & 52 & $\begin{array}{l}\text { American Lung } \\
\text { Association [38] }\end{array}$ \\
\hline & & Hispanic versus American Indian (males) & 33.9 versus 41.2 & 18 & \\
\hline & & Hispanic versus Caucasian (females) & 14.4 versus 40.9 & 65 & \\
\hline & & Hispanic versus American Indian (females) & 14.4 versus 28.3 & 49 & \\
\hline & $\begin{array}{l}\text { Lung cancer mortality rates } 1999-2003 \\
\text { (age-adjusted per } 100000 \text { per year) }\end{array}$ & Hispanic versus Caucasian (males) & 37.2 versus 73.8 & 50 & HowE [39] \\
\hline & & Hispanic versus Caucasian (females) & 14.7 versus 42.0 & 65 & \\
\hline
\end{tabular}

GOLD: Global Initiative for Chronic Obstructive Lung Disease; FEV1: forced expiratory volume in $1 \mathrm{~s}$.

cancer (odds ratio), relative to Caucasians, was 1.48 in African American subjects, 0.63 in Asian subjects and 0.48 in Hispanic subjects [41]. Although these observations in lung cancer provide the basis for the "Hispanic paradox", they may also be relevant, to a lesser degree, in other smoking-related cancers (e.g. bladder and oropharyngeal) (fig. 2) [39]. As this racial/ethnic effect persists after careful adjustment for important risk factors for lung cancer, like age and detailed smoking history, it suggests to the authors that the Hispanic paradox cannot be readily explained by differing rates of smoking [40, 41]. Moreover, the Hispanic paradox appears to extend to increased survival from nonsmall cell lung cancer in Hispanic compared with African American and non-Hispanic white subjects, despite comparable lung cancer histology and staging at diagnosis [42]. Such a finding suggests the factors underlying this paradox may be implicated in both initiation and progression of lung cancer.

Interestingly, similar inter-ethnic differences have been reported for COPD (prevalence and mortality) in a comparison of ethnic groups in the USA (table 1, and figs 1 and 3) [34, 35, 37, 43]. Comparable to the data for lung cancer, statistics for the USA suggest Hispanic subjects have lower COPD prevalence and mortality rates, even after adjustment for smoking and socioeconomic status (suggesting the Hispanic paradox extends to COPD as well as lung cancer) (table 1 and fig. 1) [34, 35, 37, 44, 45]. In one study, the reduced rates of COPD in Hispanic subjects, compared with other ethnic groups, was most marked in those of lower socioeconomic status suggesting factors other than genetic factors are relevant (see below) [34]. The finding that a low socioeconomic status in Hispanic subjects is associated with a greater protection from COPD contrasts strongly with data from other ethnic groups where the opposite is the case [37]. Such a finding suggests that other exposures traditionally linked to socioeconomic status, from occupational and/or domestic aero-pollutants, are unlikely to account for the paradoxical effect observed in Hispanic subjects. 
Importantly, when lung function decline in Hispanic subjects was compared with other ethnic groups in nonsmokers, the paradox was no longer present $[44,45]$. Similarly, in a study of female nonsmokers, lung cancer mortality rates were highest in Asian and Hispanic subjects [46]. These studies suggest the protective effect underlying the Hispanic paradox may be highly dependent on there being exposure to smoking, but much less on smoking exposure dose per se [40, 41, 44, 45].

One popular theory to explain the Hispanic paradox is that genetic factors underlie this finding $[35,44,45]$. Indeed, when the prevalence of COPD is compared among various "Hispanic" subgroups in the USA, it is notable that COPD prevalence is lowest in Hispanic Mexicans compared with Hispanic subjects from Puerto Rico and Cuba (Caribbean Hispanic), where the prevalence is closer to that observed in African Americans (fig. 3) [35]. This is perhaps not surprising, as Hispanic subjects of Caribbean origin have more African American genetic (and cultural) ancestry than the Mexican Americans who have predominantly Caucasian and Native American (Amerindian) ancestry [35, 44, 45]. However, in a recently published large cross-sectional study examining lung function and smoking in the USA, POWELL et al. [47] failed to find supporting evidence for the Hispanic paradox. In this study, the Hispanic group was only $52 \%$ Mexican and the remainder of the subjects were predominantly Caribbean Hispanic, in whom, as suggested above, there is higher COPD prevalence (fig. 3) [34] and greater African American ancestry [47, 48]. After careful matching of smoking exposure and sub-classification of Hispanic subjects by Mexican and Caribbean origin, no difference in lung function was found [49]. These data suggest that, in regards to susceptibility to COPD, the Hispanic paradox is not as consistently reported as it is for lung cancer and requires clarification in further prospective studies.

Another observation critical to unravelling the origins of the Hispanic paradox is the significant variation in COPD prevalence in Central and South America, where the rates are lowest in Mexico compared with many of its Amerindian South American neighbours [36]. As these countries share similar genetic ancestry and sociodemographic backgrounds, this finding suggests something other than genetic factors may underlie the Hispanic paradox. When genetic ancestry data are examined in detail, they show that Mexicans, like people from South American countries, have a greater proportion of Amerindian (Native American ancestry) genes than European or African genes [50]. This raises the possibility than Native American genetic ancestry may be "protective" and contribute to the lower rates of COPD in Hispanics [35]. We note for both COPD and lung cancer mortality rates, Hispanic subjects have a $\sim 30 \%$ lower rate than American Indians, substantially less than the 50-60\% reduction compared with non-Hispanic white subjects (table 1 and fig. 1) [3, 4]. As Mexican Hispanic subjects share their genetic ancestry with Native Americans, it remains possible that there is some genetic protective effect. However, Native Americans and Hispanic subjects also share some dietary preferences (cultural ancestry), such as a high consumption of legumes, so further studies will be necessary to separate these inter-ethnic effects. A study comparing Alaskan Indians with American Indians concluded that, despite similar genetic and cultural back grounds, lower smoking rates in the latter (39\% versus $21 \%$, respectively) could not explain the five- to seven-fold lower rates of lung cancer [51]. Instead, a diet low in

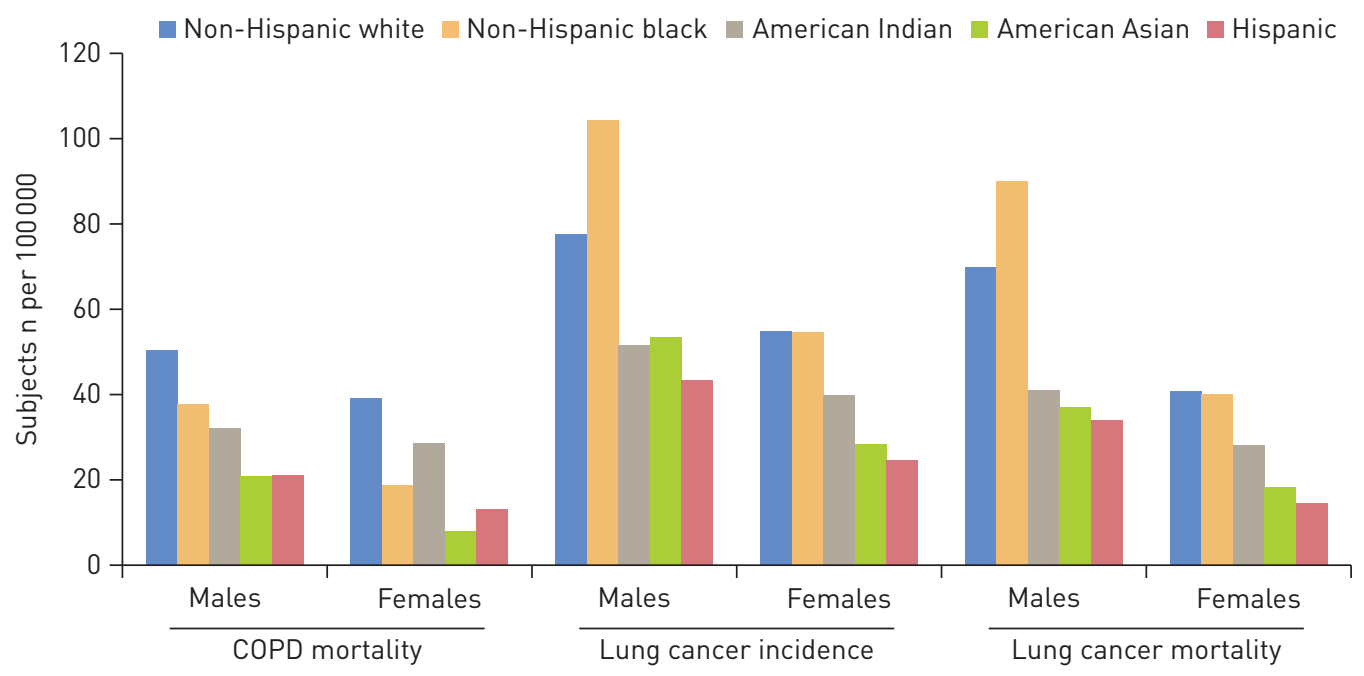

FIGURE 1 Inter-ethnic differences in mortality and/or incidence for chronic obstructive pulmonary disease (COPD) and lung cancer per 100000 , the basis of the "Hispanic paradox" [37, 38]. 
fruit, vegetables and fibre in Alaskan Indians was implicated as possibly contributing to the marked increased lung cancer rates [51].

While some have suggested the Hispanic paradox results from a differential pattern of healthy Hispanic people emigrating to the USA and older unhealthy Hispanic people returning to their home country, the evidence for this is lacking [35, 44]. Moreover, although genetic ancestry from the Iberian Peninsula (Spanish and Portuguese) is common across Central and South America, it has not been linked to lower rates of COPD or lung cancer elsewhere in the world. These observations suggest to the authors that something other than genetic factors may be at play here. An alternative hypothesis to explain the Hispanic paradox is that Hispanics have reduced COPD and lung cancer due to a protective "cultural factor" shared by the majority of smoking Hispanic subjects [44]. While two possible hypotheses have been suggested to explain the Hispanic paradox, namely a difference in genetic predisposition or difference in environmental factors $[44,48]$, the evidence for the former appears to be weak. In particular, the genetic ancestry of Hispanic Mexicans (a combination of Native American, South American Amerindian and Spanish gene pools) does not confer any clear-cut protective effect elsewhere in North America (Alaskan Indian), South America (Amerindian) or Europe (Spanish) $[35,36,51]$.

Here we present data to suggest that the increased consumption of high-fibre foods such as legumes, primarily in the form of beans, may provide an alternate explanation for the Hispanic paradox [43, 48, 52-67]. Data on bean consumption shows that Hispanic subjects, who represent $11 \%$ of the USA population, are the largest consumers of beans (accounting for 33\% of all consumption) [52]. Not only do a greater proportion of Hispanic subjects regularly consume beans compared with other ethnic groups (twice that of non-Hispanic white and African American subjects) (fig. 3) [53], but individually they consume up to four- to five-fold more beans per head of capita than white subjects $(14.24 \mathrm{~kg}(31.4 \mathrm{lbs})$ versus $2.51 \mathrm{~kg}$ (5.5 lbs) per year,
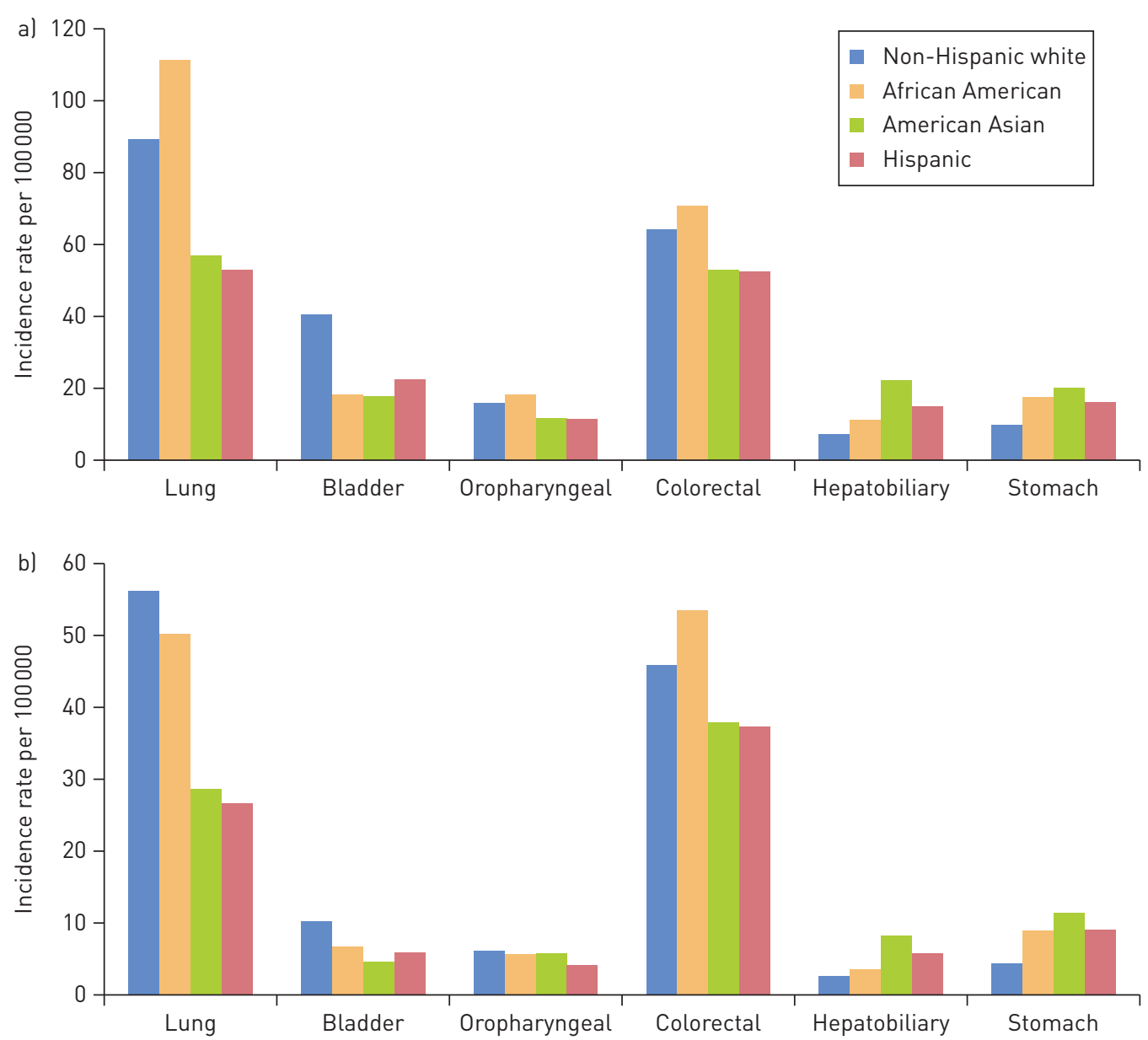

FIGURE 2 Age-adjusted incidence rates (per 100 000) for several cancers for 1999-2003 according to sex and ethnicity in the USA for a) males and b) females [39]. 


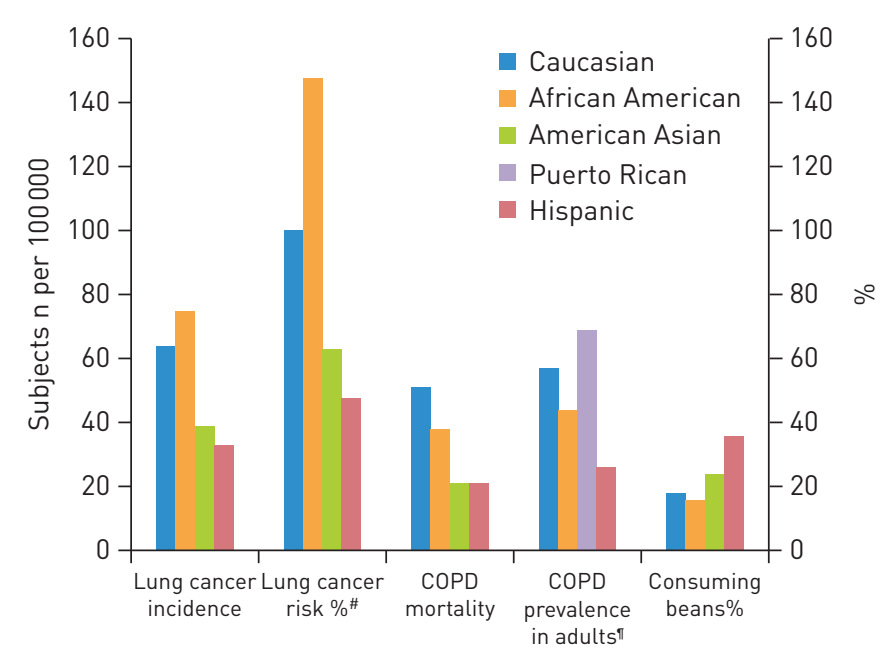

FIGURE 3 Lung cancer incidence per 100000 [38], adjusted lung cancer risk [41], chronic obstructive pulmonary disease (COPD) mortality per 100000 [37], COPD prevalence in adults [34] and percentage consuming bean [43] in the USA according to ethnicity. ${ }^{\#}$ : odds ratio $\times 100 ; \%$ : \% $\times 10$.

respectively) [43]. The key question now becomes, how might an increased consumption of beans affect a smoker's susceptibility to COPD or lung cancer?

\section{Legumes/beans and systemic inflammation}

As stated above, the consumption of fruit and vegetables has been shown to be protective against COPD and lung cancer $[5,6]$. This has been attributed to an antioxidant or anti-inflammatory effect according to many epidemiological, animal and in vitro studies [5, 6]. However, the specific food group and biological mechanism underlying this effect has not yet been clearly identified. Several studies have linked a lower incidence of lung cancer to the consumption of phyto-oestrogens, suggesting that the oestrogenic effect of this food group may confer hormonal protective effects [54-58]. In a very detailed analysis of the dietary intake of lung cancer cases compared with controls carefully matched for age, sex, ethnicity and smoking, SCHABATH et al. [54] reported that consumption of phyto-oestrogens reduced lung cancer risk in a doseresponse relationship. Further analysis of this observation revealed that it was due to differences in consumption of soybean in particular, over that of fruit and vegetables, or lignin containing (tea and coffee) sources [54]. While this apparent "protective effect" was evident in lifelong nonsmokers, it was two-fold greater in current and former smokers [54]. This suggested to the authors that an important diet-smoking interactive effect was at play that partly attenuated the adverse effects of smoking on the lungs. We have observed a similar effect with statin therapy in several large observational studies [16, 32]. The diet-smoking effect we describe, mediated through attenuation of systemic inflammation, might also explain why the Hispanic paradox is most obvious across several smoking-related diseases (ie. lung cancer, COPD and bladder cancer) (fig. 2), and why the protective effect on lung function decline and lung cancer mortality was reduced or lost in nonsmokers [45]. Interestingly, the diet-smoking effect in the study by SCHABATH et al. [54] was strongest in males compared with females, suggesting an oestrogen-based modifying effect. However, in contrast to SСHАBATH et al. [54], we suggest that the consumption of high fibre legumes, primarily from bean-based sources, best explain their observations. We also suggest that it is the antiinflammatory effect of legumes that explain their observation (rather than phytoestrogenic effects) and that this effect underlies the Hispanic paradox. However, it remains a possibility that other sources of antioxidants (e.g. quercetin from apples) are important in the Hispanic paradox, although data to support such a hypothesis are currently lacking.

Legumes are very high in fibre and have been previously linked to a reduced risk of COPD and lung cancer through the antioxidant properties of fibre [59-61]. Although previous epidemiological studies have implicated the antioxidant effects of flavonoids (especially from apples, tea and pears) in reducing lung function decline $[62,63]$, increased dietary fibre has been linked to reduced respiratory symptoms [64], better lung function $[59,60]$ and reduced respiratory mortality $[65,66]$. Surprisingly, in the study on mortality [65], the protective effect conferred by a high fibre diet was greater for respiratory deaths than for cardiovascular disease and cancer, further implicating an anti-inflammatory mechanism [66]. Importantly, the beneficial effect of fibre on lung function and respiratory mortality was independent of smoking, sex, 
ethnicity, vitamin (carotenoid) intake and other potential confounding variables [60,65]. Consumption of legumes has recently been linked to a significant reduction in systemic inflammation $[67,68]$. In a crosssectional study of 486 females, reductions in both IL-6 and CRP were noted in those taking a diet rich in fruit, vegetables, tea, grains and legumes [67]. When this dietary effect was explored in greater detail in a subsequent analysis, high legume consumption (lentils, peas, chickpeas and beans) was found to be associated with reductions in IL- 6 and CRP of 30-50\% in the highest tertile compared with the lowest tertile of legume consumption [68]. This finding is supported by prospective interventional data from a randomised crossover feeding trial showing a high-legume based diet significantly lowered CRP levels [69]. This legume-mediated reduction in CRP (and IL-6) is clinically significant and comparable to that seen with statin therapy [16]. That this anti-inflammatory effect is mediated through the high fibre content of legumes is supported by numerous cross-sectional and longitudinal studies that have shown high-fibre diets are associated with lower systemic inflammation [70-72]. We conclude that there is substantial evidence supporting the proposition that high legume consumption has an anti-inflammatory effect that is probably mediated through its high fibre content.

We have previously noted that an increase in systemic inflammation, characterised by elevated IL-6 or CRP levels, has been linked to an increased risk of both COPD and lung cancer (fig. 4) [15-27]. Moreover, a reduction in IL-6-mediated systemic inflammation, through the use of HMGCoA reductase inhibitors (statins), has been closely linked to improved outcomes and reduced mortality in COPD, and to reduced mortality and prevalence of lung cancer $[16,32]$. We propose that the Hispanic paradox results in part from a high consumption of dietary fibre (primarily from legume consumption) causing attenuation of systemic inflammation $[59,60]$. Diets high in fibre are known to increase the concentration of small-chain fatty acids (SCFAs) in the blood (notably acetate, propionate and butyrate) [73, 74]. These SCFAs have established anti-inflammatory effects, lowering systemic inflammation (IL-6 and CRP levels) through their inhibition of HMGCoA reductase, with downstream inhibition of the pro-inflammatory transcription factor nuclear

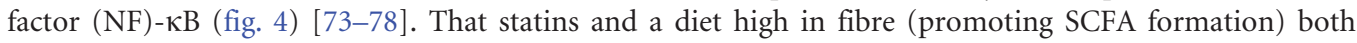
appear to effectively attenuate systemic inflammation through HMGCoA reductase inhibition [16, 73, 74, 78], and reduce lung cancer incidence by nearly $50 \%$ [16], is both surprising and potentially of considerable public health interest. While past epidemiological studies have spuriously associated high intakes of vitamins ( $\beta$-carotene and $\alpha$-tocopherol) with a lower risk of lung cancer [61], it may have been the high fibre in these vitamin-rich diets and not the vitamins that actually conferred the protective effect. The anti-inflammatory and anti-neoplastic effects of colonic SCFAs are thought to underlie the protective effect of fibre in bowel cancer [78]. However, SCFAs found in the systemic circulation, and derived from the combined effects of dietary fibre and colonic bacteria $[73,74]$, may have several relevant protective functions in COPD and lung cancer. These include attenuation of innate immunity through effects on the regulation/migration of neutrophils $[73,74]$, epithelial protection against bacterial infection [76] and anti-proliferative effects through

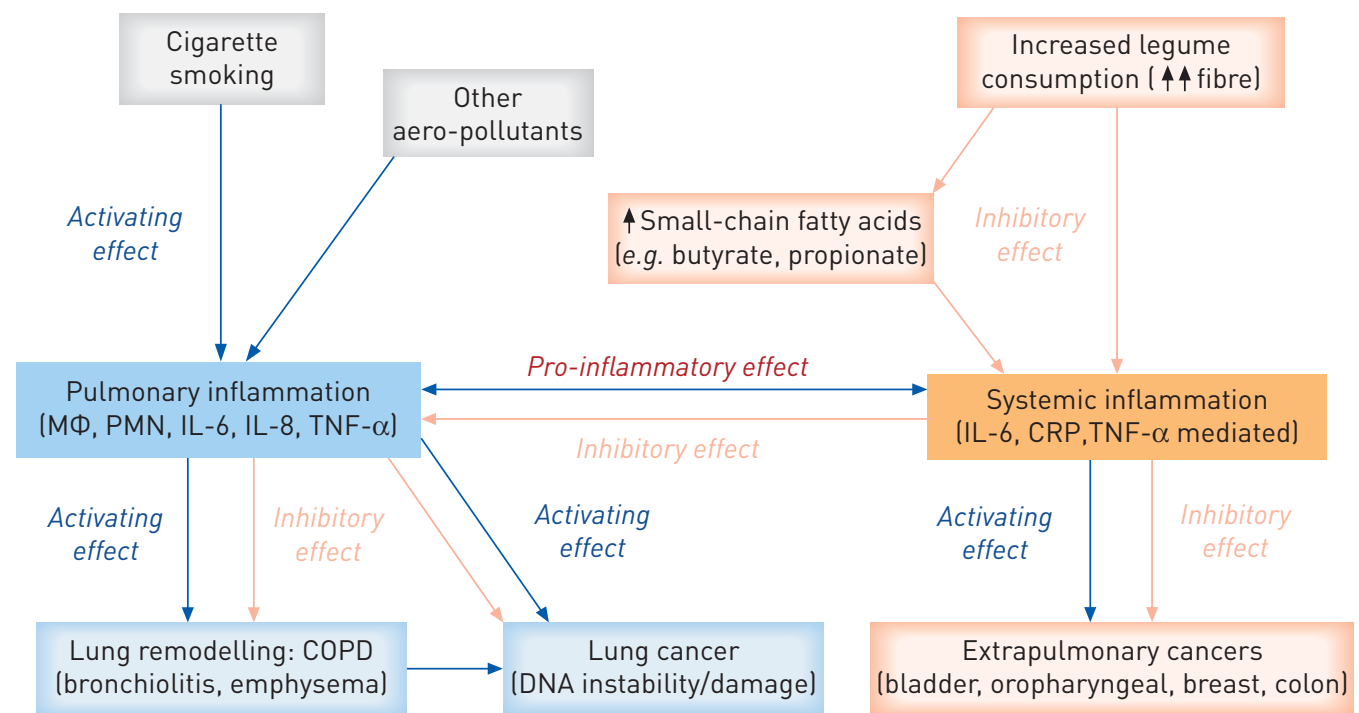

FIGURE 4 Schematic of the relationship between smoking and legume consumption (smoking-diet relationship) in relation to pulmonary inflammation, systemic inflammation, chronic obstructive pulmonary disease (COPD) and cancer (both lung and extrapulmonary). MФ: macrophage; PMN: polymorphonuclear neutrophil; IL: interleukin; TNF: tumour necrosis factor; CRP: C-reactive protein. 
inhibition of histone deacetylase [73, 75, 77]. Given the bidirectional effects of smoking-initiated airway inflammation and systemic inflammation driving aberrant repair processes and lung remodelling (fig. 4), it is conceivable that diet-induced suppression of systemic inflammation could have wide reaching effects on the lung, particularly in lighter smokers (e.g. Hispanic Mexicans). We suggest these mechanisms provide the most plausible explanation of how a diet high in legumes (or fibre) might partially protect against smoking-induced respiratory disease, although other possibilities have been proposed [54, 60, 68]. We conclude that, while more research is needed to better understand the link between high fibre (legume or bean) consumption and the lowering of systemic inflammation, we favour an anti-inflammatory or immune-modulatory effect mediated through inhibition of the NF- $\mathrm{KB} / \mathrm{IL}-6 / \mathrm{CRP}$ inflammatory pathway. Our final question is: are there any other ethnic groups where the risk of COPD or lung cancer may be affected by diet?

\section{Other ethnic groups and the consumption of legumes}

Lower rates of COPD and lung cancer have also been observed in Asians in the USA (figs 1-3) [3,4] raising the possibility that diet may also be relevant to this group [34,37-39, 40]. The lower risk of lung cancer in Asians was confirmed in a recently published lung cancer screening study (odds ratio of 0.63 compared with Caucasians), where age, smoking history and sociodemographic variables were carefully accounted for in the analysis (see earlier) [41]. Moreover, USA data on bean consumption suggests Asians are also high consumers of legumes, in particular soy products $[43,52-55,59,79]$. This is because soy products (e.g. tofu) are derived from the soybean and may confer the same protective effect as legumes (attenuation of systemic inflammation as outlined above) $[54,55]$. We, therefore, suggest that the lower incidence of both COPD and lung cancer in American Asians (figs 1-3) may also result, in part, from the beneficial effects of a high fibre and legume (soy-based) diet. By contrast, for African Americans, where low intake of fruit and vegetables has been reported, the increased prevalence of COPD and lung cancer cannot be explained by a difference in bean consumption [51,52]. Although other dietary or lifestyle factors may contribute to an increased risk of COPD and lung cancer in African Americans [35, 47], genetic effects linked to elevated systemic inflammation remain a possibility [80].

\section{Conclusion}

This article has proposed that there are several lines of indirect evidence supporting the hypothesis that consumption of fibre, and specifically beans or bean-based products (soy and tofu), might have a beneficial effect in Hispanic subjects (and possibly Asians) who smoke, explaining, in part, their lower mortality of COPD and lung cancer. The data, to date, suggest this effect might result from the anti-inflammatory effects of this food group, specifically the attenuation of systemic inflammation implicated in COPD and lung cancer. This "systemic inflammation hypothesis" [15, 16, 31, 33] is supported by the observation that Hispanic subjects, compared to non-Hispanic white subjects, have improved survival from lung cancer, colon cancer and breast cancer [1,2,37-39]; the latter two are linked to systemic inflammation through obesity. However, this beneficial effect does not extend to liver or stomach cancer (fig. 2) [39]. Hispanics also have better survival from cardiovascular disease, which is known to be linked with elevated systemic inflammation $[15,16]$.

As described above, an interesting observation that provides indirect evidence linking lowering of systemic inflammation with lower rates of COPD and lung cancer comes from several studies on the use of HMGCoA reductase inhibitors [16]. These drugs are potent inhibitors of systemic inflammation and have been strongly linked, in observational studies, to reduced mortality in COPD and reduced prevalence of lung cancer [16]. We propose that a similar protective immune-modulatory effect may occur with regular consumption of legumes (fibre) and that this effect might also be mediated through the same underlying mechanism, inhibition of the HMGCoA reductase enzyme. In addition to lowering cholesterol, inhibition of HMGCoA reductase blocks signalling molecules called guanosine triphosphatases (Rho, Ras and Rac)

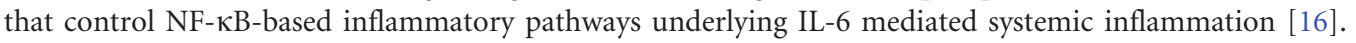

Our hypotheses can be tested in large prospective cohort studies and clinical intervention trials where accurate dietary intake is recorded and outcomes carefully documented. We suggest that this hypothesis should be examined as the public health implications of such a finding are considerable. While cigarette smoking remains a tolerated, albeit increasingly marginalised, lifestyle choice in developed countries, its legacy in both current and former smokers will persist long into the future in the form of COPD and lung cancer. This is important because the risk of COPD and lung cancer remains high in ex-smokers even decades after quitting. The increasing burden of these diseases in developing countries remains a concern. While diets high in fruit, vegetables and fish are generally recommended, it may be that legumes (with a high fibre content) in particular confer specific protective effects in current or former smokers. We believe this hypothesis requires investigation in prospective studies. 


\section{References}

$1 \quad$ American Cancer Society. www.cancer.org Date last accessed: July 26, 2013.

2 Emphysema Foundation For Our Right To Survive. Creation of a COPD Program at CDC. www.emphysema. net/cdc_copd_program.htm Date last accessed: July 26, 2013.

3 Mattson ME, Pollack ES, Cullen JW. What are the odds that smoking will kill you? Am J Public Health 1987; 77: 425-431.

4 Kohansal R, Martinez-Camblor P, Agustí A, et al. The natural history of chronic airflow obstruction revisited: an analysis of the Framingham Offspring Cohort. Am J Respir Crit Care Med 2009; 180: 3-10.

5 Varraso R, Fung TT, Hu FB, et al. Prospective study of dietary patterns and chronic obstructive pulmonary disease among US men. Thorax 2007; 62: 786-791.

6 Buchner FL, Bueno-de-Mesquita HB, Ros MM, et al. Variety in fruit and vegetable consumption and the risk of lung cancer in the European prospective investigation into cancer and nutrition. Cancer Epidemiol Biomarkers Prev 2010; 19: 2278-2286.

$7 \quad$ Young RP, Hopkins RJ, Etzel C, et al. Genetics of lung cancer susceptibility and COPD. Lancet Oncol 2011; 12: 622-623.

8 Wilson DO, Weissfeld JL, Balkan A, et al. Association of radiographic emphysema and airflow obstruction with lung cancer. Am J Respir Crit Care Med 2008; 178: 738-744.

9 Young RP, Hopkins RJ, Christmas T, et al. COPD prevalence is increased in lung cancer independent of age, sex and smoking history. Eur Respir J 2009; 34: 380-386.

10 Woloshin S, Schwartz LM, Welch HG. The risk of death by age, sex, and smoking status in the United States: putting health risks in context. J Natl Cancer Inst 2008; 100: 845-853.

11 Gershon AS, Warner L, Cascagnette P, et al. Lifetime risk of developing chronic obstructive pulmonary disease: a longitudinal population study. Lancet 2011; 378: 991-996.

12 Young RP, Hopkins RJ, Hay BA, et al. Lung cancer gene associated with COPD: triple whammy or possible confounding effect? Eur Respir J 2008; 32: 1158-1164.

13 Young RP, Whittington CF, Hopkins RJ, et al. Chromosome 4q31 locus in COPD also associated with lung cancer. Eur Respir J 2010; 36: 1375-1382.

14 Tetley TD. Macrophages and the pathogenesis of COPD. Chest 2002; 121: Suppl., 156S-159S.

15 Sinden NJ, Stockley RA. Systemic inflammation and comorbidity in COPD: a result of "overspill" of inflammatory mediators from the lungs? Review of the evidence. Thorax 2010; 65: 930-936.

16 Young RP, Hopkins R, Eaton TE. Pharmacological actions of statins: potential utility in COPD. Eur Respir Rev 2009; 18: 222-232.

17 Kony S, Zureik M, Driss F, et al. Association of bronchial hyperresponsiveness and lung function with C-reactive protein (CRP): a population based study. Thorax 2004; 59: 892-896.

18 Hancox RJ, Poulton R, Greene JM, et al. Systemic inflammation and lung function in young adults. Thorax 2007; 62: 1064-1068.

19 Gimeno D, Delclos GL, Ferrie JE, et al. Association of CRP and IL-6 with lung function in a middle-aged population initially free from self-reported respiratory problems: the Whitehall II study. Eur J Epidemiol 2011; 26: 135-144.

20 Thomsen M, Ingebrigtsen TS, Marott JL, et al. Inflammatory biomarkers and exacerbations in chronic obstructive pulmonary disease. JAMA 2013; 309: 2353-2361.

21 Dahl M, Vestbo J, Lange P, et al. C-reactive protein as a predictor of prognosis in chronic obstructive pulmonary disease. Am J Respir Crit Care Med 2007; 175: 250-255.

22 Walter RE, Wilk JB, Larson MG, et al. Systemic inflammation and COPD: the Framingham Heart Study. Chest 2008; 133: 19-25.

23 Il'yasova D, Colbert LH, Harris TB, et al. Circulating levels of inflammatory markers and cancer risk in the health aging and body composition cohort. Cancer Epidemiol Biomarkers Prev 2005; 14: 2413-2418.

24 Siemes C, Visser LE, Coebergh JW, et al. C-Reactive protein levels, variation in the C-reactive protein gene, and cancer risk: the Rotterdam study. J Clin Oncol 2006; 24: 5216-5222.

25 Allin KH, Bojesen SE, Nordestgaard BG. Baseline C-reactive protein is associated with incident cancer and survival in patients with cancer. J Clin Oncol 2009; 27: 2217-2224.

26 Chaturvedi AK, Caporaso NE, Katki HA, et al. C-reactive protein and risk of lung cancer. J Clin Oncol 2010; 28: 2719-2726.

27 Ko YJ, Kwon YM, Kim KH, et al. High-sensitivity C-reactive protein levels and cancer mortality. Cancer Epidemiol Biomarkers Prev 2011; 21: 2076-2086.

28 Kuhn C, Homer RJ, Zhu Z, et al. Airway responsiveness and airway obstruction in transgenic mice. Morphologic correlates in mice overexpressing IL-11 and IL-6 in the lung. Am J Respir Cell Mol Biol 2000; 22: $289-295$.

29 Miyata R, Bai N, Vincent R, et al. Statins reduce ambient particulate matter-induced lung inflammation by promoting the clearance of particulate matter $<10 \mu \mathrm{m}$ from lung tissues. Chest 2013; 143: 452-460.

30 Arimura K, Aoshiba K, Tsuji T, et al. Chronic low-grade systemic inflammation causes DNA damage in the lungs of mice. Lung 2012; 190: 613-620.

31 Young RP, Hopkins RJ. Statins reduce lung inflammation by promoting the clearance of particulate matter from lung tissues. Chest 2013; 144: 358-359.

32 Nielson SF, Nordestggard BG, Bojesin SE. Statin use and reduced cancer-related mortality. N Engl J Med 2012; 367: 1792-1802.

33 Young RP, Hopkins RJ. Interleukin-6 and statin therapy: potential role in the management of COPD. Respir Res 2013; 14: 74

34 Akinbami LJ, Liu X. Chronic obstructive pulmonary disease among adults aged 18 and over in the United States, 1998-2009. NCHS Data Brief, no 63. Hyattsville, National Center for Health Statistics, 2011.

35 Bruse S, Sood A, Petersen H, et al. New Mexican Hispanic smokers have lower odds of chronic obstructive pulmonary disease and less decline in lung function than non-Hispanic whites. Am J Respir Crit Care Med 2011; 184: $1254-1260$

36 Menzes AM, Perez-Padella R, Jardim JR, et al. Chronic obstructive pulmonary disease in five Latin American cities (the PLATINO study): a prevalence study. Lancet 2005; 366: 1875-1881. 
37 American Lung Association. Chronic obstructive pulmonary disease (COPD). In: State of Lung Disease in Diverse Communities 2010. Washington, American Lung Association, 2010.

38 American Lung Association, Epidemiology and Statistics Unit, Research and Program Services Division. Trends in Lung Cancer Morbidity and Mortality. American Lung Association, March 2010. www.lung.org/z-testing-2/ finding-cures/our-research/trend-reports/lc-trend-report.pdf

39 Howe HL, Wu X, Ries LA, et al. Annual report to the nation on the status of cancer, 1975-2003, featuring cancer among U.S. Hispanic/Latino populations. Cancer 2006; 107: 1711-1742.

40 Haiman CA, Stram DO, Wilkens LR, et al. Ethnic and racial differences in the smoking-related risk of lung cancer. N Engl J Med 2006; 354: 333-342.

41 Tammemägi MC, Katki HA, Hocking WG, et al. Selection criteria for lung-cancer screening. N Engl J Med 2013; 368: 728-736.

42 Saeed AM, Toonkel R, Glassberg MK, et al. The influence of Hispanic ethnicity on nonsmall cell lung cancer histology and patient survival: an analysis of the Survival, Epidemiology, and End Results database. Cancer 2012; 118: 4495-4501.

43 Northarvest Bean Growers Association. Love those beans! www.northarvestbean.org/html/news.cfm?ID=559 Date last accessed: August 12, 2013.

44 Drummond MB. The Hispanic paradox unraveled? Am J Respir Crit Care Med 2011; 184: 1222-1223.

45 Vollmer WM, Enright PL, Pedula KL, et al. Race and gender differences in the effects of smoking on lung function. Chest 2000; 117: 764-772.

46 Gomez SL, Chang ET, Shema SJ. Survival following non-small cell lung cancer among Asian/Pacific Islander, Latina, and Non-Hispanic white women who have never smoked. Cancer Epidemiol Biomarkers Prev 2011; 20: $545-554$.

47 Powell R, Davidson D, Divers J, et al. Genetic ancestry and the relationship of cigarette smoking to lung function and per cent emphysema in four race/ethnic groups: a cross-sectional study. Thorax 2013; 68: 634-642.

48 Young RP, Hopkins RJ. The Hispanic paradox further unraveled? Thorax 2014; 69: 184-185.

49 Powell R, Barr RG. Response letter to: the Hispanic paradox further unraveled? Thorax 2014; 69: 185-186.

50 Bryc K, Velez C, Karafet T, et al. Genome-wide patterns of population structure and admixture among Hispanicl Latino populations. Proc Natl Acad Sci USA 2010; 107: Suppl. 2, 8954-8961.

51 Kelly JJ, Lanier AP, Alberts S, et al. Differences in cancer incidence among Indians in Alaska and New Mexico and U.S. Whites, 1993-2002. Cancer Epidemiol Biomarkers Prev 2006; 15: 1515-1519.

52 Lucier G, Lin B-H, Allshouse J, et al. Factors affecting dry bean consumption in the United States. Vegetables and Specialties SeO 2000; /VGS-280/April: 26-34.

53 Mitchell DC, Lawrence FR, Hartman TJ, et al. Consumption of dry beans, peas, and lentils could improve diet quality in the US populations. J Am Diet Assoc 2009; 109: 909-913.

54 Schabath MB, Hernandez LM, Wu X, et al. Dietary phytoestrogens and lung cancer risk. JAMA 2005; 294: 1493-1504.

55 Yang G, Shu XO, Li HL, et al. Pre-diagnosis soy food consumption and lung cancer survival in women. J Clin Oncol 2013; 31: 1548-1553.

56 Yang WS, Va P, Wong MY, et al. Soy intake is associated with lower lung cancer risk: results from a meta-analysis of epidemiologic studies. Am J Clin Nutr 2011; 94: 1575-1583.

57 Knekt P, Järvinen R, Seppänen R, et al. Dietary flavonoids and the risk of lung cancer and other malignant neoplasms. Am J Epidemiol 1997; 146: 223-230.

58 Seow A, Poh WT, Teh M, et al. Diet, reproductive factors and lung cancer risk among Chinese women in Singapore: evidence for a protective effect of soy in nonsmokers. Int J Cancer 2002; 97: 365-371.

59 Varraso R, Willett WC, Camargo CA Jr. Prospective study of dietary fiber and risk of chronic obstructive pulmonary disease among US women and men. Am J Epidemiol 2010; 171: 776-784.

60 Kan H, Stevens J, Heiss G, et al. Dietary fiber, lung function, and chronic obstructive pulmonary disease in the atherosclerosis risk in communities study. Am J Epidemiol 2008; 167: 570-578.

61 Kromhout D, Bosschieter EB, De Lezenne Coulander C. Dietary fibre and 10-year mortality from coronary heart disease, cancer, and all causes. The Zutphen study. Lancet 1982; 2: 518-522.

62 Butland BK, Fehily AM, Elwood PC. Diet, lung function, and lung function decline in a cohort of 2512 middle aged men. Thorax 2000; 55: 102-108.

63 Tabak C, Arts ICW, Smit HA, et al. Chronic obstructive pulmonary disease and intake of catechins, flavanols, and flavones: the MORGEN Study. Am J Respir Crit Care Med 2001; 164: 61-64.

64 Butler LM, Koh PW, Lee HP, et al. Dietary fibre and reduced cough with phlegm: a cohort study in Singapore. Am J Respir Crit Care Med 2004; 170: 279-287.

65 Park YY, Subar AF, Hollenbeck A, et al. Dietary fiber intake and mortality in the NIH-AARP diet and health study. Arch Intern Med 2011; 171: 1061-1068.

66 de Koning L, Hu FB. Do the health benefits of dietary fibre extend beyond cardiovascular disease? Arch Intern Med 2011; 171: 1069-1070.

67 Esmaillzadeh A, Kimiagar M, Mehrabi Y, et al. Dietary patterns and markers of systemic inflammation among Iranian women. J Nutr 2007; 137: 992-998.

68 Esmaillzadeh A, Azadbakht L. Legume consumption is inversely associated with serum concentrations of adhesion molecules and inflammatory biomarkers among Iranian women. J Nutr 2012; 142: 334-339.

69 Hartmann TJ, Albert PS, Zhang Z, et al. Consumption of a legume-enriched low-glycemic index diet is associated with biomarkers of insulin resistance and inflammation among men at risk for colorectal cancer. J Nutr 2010; 140: 60-67.

70 King DE, Egan BM, Geesey ME. Relation of dietary fat and fiber to elevation of C-reactive protein. Am J Cardiol 2003; 92: 1335-1339.

71 Ma Y, Griffith JA, Chasan-Taber L, et al. Association between dietary fiber and serum C-reactive protein. Am J Clin Nutr 2006; 83: 760-766.

72 Ma Y, Hébert JR, Li W, et al. Association between dietary fiber and markers of systemic inflammation in the Women's Health Initiative Observational Study. Nutrition 2008; 24: 941-949. 
73 Meijer K, de Vos P, Priebe MG. Butyrate and other short-chain fatty acids as modulators of immunity: what relevance for health? Curr Opin Nutr Metab Care 2010; 13: 715-721.

74 Finley JW, Burrell JB, Reeves PG. Pinto bean consumption changes SCFA profiles in fecal fermentations, bacterial populations of the lower bowel, and lipid profiles in blood of humans. J Nutr 2007; 137: 2391-2398.

75 Maslowski KM, Vieira AT, Ng A, et al. Regulation of inflammatory responses by gut microbiota and chemoattractant receptor GPR43. Nature 2009; 461: 1282-1286.

76 Fukuda S, Toh H, Hase K, et al. Bifidobacteria can protect from enteropathogenic infection through production of acetate. Nature 2011; 469: 543-547.

77 Ahmad M, Hamid A, Hussain A, et al. Understanding histone deacetylases in the cancer development and treatment: an epigenetic perspective of cancer chemotherapy. DNA Cell Biol 2012; 31: Suppl. 1, S62-S72.

78 Trinidad TP, Mallillin AC, Loyola AS, et al. The potential health benefits of legumes as a good source of dietary fibre. Br J Nutr 2010; 103: 569-574.

79 Hirayama F, Lee AH, Binns CW, et al. Soy consumption and risk of COPD and respiratory symptoms: a casecontrol study in Japan. Respir Res 2009; 10: 56.

80 Reiner AP, Beleza S, Franceschini N, et al. Genome-wide association and population genetic analysis of C-reactive protein in African American and Hispanic American women. Am J Human Genetics 2012; 91: 502-512. 